\title{
HIDROLOGIA E FITOPLÂNCTON DO SISTEMA ESTUARINO DO RIO SÃO FRANCISCO, NORDESTE DO BRASIL
}

\author{
Marluce Rocha Melo e SOUZA ${ }^{1}$ \\ Maria da Glória Gonçalves da SILVA CUNHA ${ }^{2}$ \\ Manuel de Jesus Flores MONTES ${ }^{2}$ \\ Sigrid NEUMANN LEITÃ ${ }^{2}$ \\ Fernando de Figueiredo PORTO NETO ${ }^{2}$ \\ Mauro Cés ar de Oliveira MOURA ${ }^{2}$ \\ Cláudia Castelo Branco CHAMIXAES LOPEZ ${ }^{3}$ \\ -IBAMA- SERGIPE \\ ${ }^{2}$ Departamento de Oceanografia da UFPE \\ ${ }^{3}$ Departamento de Botânica da UFPE
}

\section{RESUMO}

Estudos foram realizados no estuário do rio São Francisco, em Brejo Grande, Sergipe (Brasil) em 997 e 1998, objetivando diagnosticar as condições ambientais. Dados climáticos foram obtidos na Estação de Meteorologia de Propriá. Dados hidrológicos e fitoplanctônicos foram coletados em duas estações fixas no baixo São Francisco, uma à montante e outra à jusante do município de Brejo Grande. Amostragens foram feitas nos períodos chuvoso (agosto/97) e seco (janeiro/98), a cada $3 \mathrm{~h}$, num ciclo completo de marés. Os dados climatológicos confirmaram os dois períodos anuais seco e chuvoso, sendo este último atípico nos últimos anos devido às baixas taxas registradas. A vazão média do rio foi diminuindo de $1993\left(2.592 \mathrm{~m}^{3} . \mathrm{s}^{-1}\right)$ a $1996\left(1742 \mathrm{~m}^{3} \cdot \mathrm{s}^{-1}\right)$ voltando a aumentar em $1997\left(1870 \mathrm{~m}^{3} \cdot \mathrm{s}^{-1}\right)$. Menores vazões ocorreram junho/julho e maiores em janeiro, fato associado aos períodos de chuvas à montante do rio, que é no verão. Dos dados hidrológicos, a salinidade apresentou maiores variações, com regime totalmente limnético no período chuvoso e polialino no período seco, com valor máximo de $27,35 \%$ o. Os nutrientes, principalmente o nitrato, apresentaram maiores quantidades no período chuvoso, quando há maior lixiviação. A biomassa planctônica foi baixa, indicando área pouco produtiva. A produção do fitoplâncton foi maior no período seco, quando a maior transparência da água permitiu maior atividade fotossintética. Foram identificadas 59 espécies fitoplanctônicas, sendo que no período chuvoso houve predomínio de diatomáceas e no período seco de clorofíceas. Dentre as diatomáceas destacaram-se Aulacoseira granulata e Aulacoseira islandica f. curvata e dentre as clorofíceas Dimorphococcus sp e Staurastrum leptocladum.

Palavras-chave: Hidrologia, fitoplâncton, estuário, rio Sâo Freancisco

\section{ABSTRACT \\ Hydrology and Phytoplankton of the River São Francisco Estuarine System, Northeat Brazil}

Studies were carried out in the estuary of the River São Francisco, near Brejo Grande town, Sergipe (Brasil), in 1997 and 1998, in order to evaluate the environmntal 
condition. Climatic data were obtained at the Meteorological Station at Propriá. Hydrological and phytoplanktonic data were collected in two fixed stations one upstream and other downstream of Brejo Grande town. Samplings were carried out in the rainy (August/97) and dry (Jannuary/98) seasons, each $3 \mathrm{~h}$, in a complete tidal cycle. Climatological data confirmed the two seasons: the dry and the rainy, although last years have been atypical because low rain taxa. The average river discharge decreased from $1993\left(2592 \mathrm{~m}^{3} . \mathrm{s}^{-1}\right)$ to $1996\left(1742 \mathrm{~m}^{3} . \mathrm{s}^{-1}\right)$ increasing in $1997\left(1870 \mathrm{~m}^{3} . \mathrm{s}^{-1}\right)$. Lower discharge occurred in June/July and higher in Jannuary, due rainy season upstream headwater that is in summer. Salinity varied a lot with a limnetic regime at the rainy season and polihaline regime during the dry season, with a maximun of $27,35 \%$ o. The nutrients, mainly nitrate, presented higher quantities at the rainy season, when higher lixiviation is present. The planktonic biomass of the microplankton was low, indicating low productivity. Phytoplankton production was higher in the dry season, when higher water transparency allows higher phytoplankton photosintetic activity. It was identified 59 species; at the rainy season domitated the diatoms and in the dry season the green algae. The most abundant diatoms were Aulacoseira granulata and Aulacoseira islandica f. curvata; among the green algae outranked Dimorphococcus sp.

Key words: Hydrology, phytoplankton, estuary, River São Francisco

\section{INTRODUÇÃO}

Entre os principais ecossistemas naturais no Brasil que têm a estabilidade ecológica ameaçada estão os estuários, que se caracterizam por altas taxas de produção primária e secundária e pela alta complexidade ecológica, reflexo da grande diversidade de funções de força atuantes. Trata-se de um ecótono entre os habitats marinhos e de água doce, sem esquecer a forte influência terrestre. Em conseqüência, seus limites não são bem definidos, estendendo-se os processos hidrodinâmicos além das áreas de influência da salinidade. Desta forma, muitos dos seus atributos abióticos e bióticos mais importantes não são transitórios, e sim, exclusivos (Day Jr e Yáñez-Arancibia, 1982; Ketchum, 1983; Odum, 1985).

A área estuarina do rio São Francisco, localizada na região norte de Sergipe, tem sido submetida a diversos impactos, entre os quais a construção de barragens à montante do rio, a retirada de grandes volumes d'água para a irrigação da agricultura, a construção de um porto ao sul da foz do São Francisco, a carga de esgotos domiciliares e drenagem de fertilizantes da agroindústria lançados ao longo do rio. Além destes, a área do baixo São Francisco, principalmente na sua desembocadura, tem estado sujeita a intensas mudanças geomorfológicas, alterando as características físicas, químicas e biológicas, com grandes prejuízos sócio-econômicos.

Visando fazer um diagnóstico ambiental do rio São Francisco, foi elaborada esta pesquisa que aborda os aspectos hidrológicos e fitoplanctônicos da área estuarina próxima ao município de Brejo Grande, Sergipe.

\section{MATERIAL E MÉTODOS}

A área estuarina do rio São Francisco, presentemente estudada pertence ao município de Brejo Grande, na microregião de Propriá, estado de Sergipe, na posição 
oriental da região Nordeste do Brasil. Localiza-se nas seguintes coordenadas geográficas: latitudes de $10^{0} 24^{\prime} 49^{\prime \prime}$ e $10^{0} 33^{\prime} 17^{\prime \prime} \mathrm{S}$ e longitudes $36^{0} 23^{\prime} 41^{\prime \prime}$ e $36^{\circ} 34^{\prime} 23^{\prime \prime}$ W (Fig. 1).

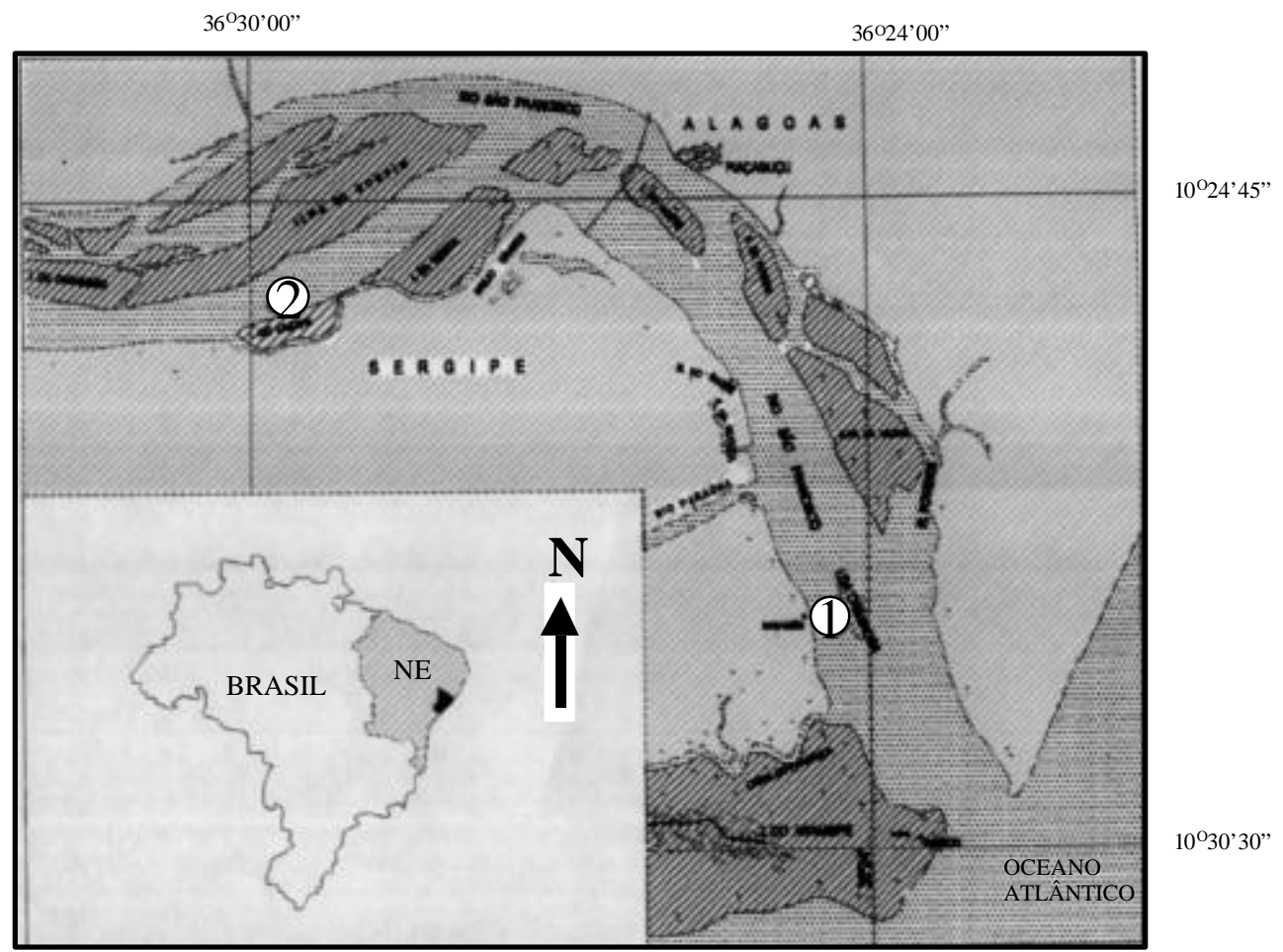

Figura 1 - Localização da área e estações de coleta, no sistema estuarino do rio São Francisco. 
Os dados do clima foram obtidos na Estação de Meteorologia de Propriá, inserida na Zona do baixo São Francisco, em Sergipe, situada mais próxima à área estudada. Foram obtidos dados médios referentes a 30 anos (1961-1990).

Os dados hidrológicos foram obtidos em duas estações fixas no estuário do rio São Francisco, uma à montante e outra à jusante do município de Brejo Grande, Sergipe. As amostragens foram feitas em agosto/1997 (período chuvoso) e janeiro/1998 (período seco), em duas profundidaades, a cada 3 horas, num ciclo de 12 horas.

As alturas das marés foram obtidos na Tábuas das Marés publicadas pela Diretoria de Hidrografia e Navegação, Marinha do Brasil, para o Porto de Aracaju considerando os dias das coletas. A profundidade local foi medida em cada estação com ecobatímetro. A transparência da água foi medida através do lançamento do disco de Secchi, e registrada a profundidade máxima visualizada. A temperatura da água foi obtida pela leitura direta do termômetro de reversão acoplado à garrafa de Nansen. A salinidade foi determinada pelo método Mohr-Knudsen, descrito por Strickland e Parsons (1965). A concentração hidrogeniônica foi determinado por meio de um potenciômetro de marca Metronal pH metro E120. O oxigênio dissolvido foi determinado pelo método de Winkler, descrito por Strickland e Parsons (1965). Os nutrientes (nitrito, nitrato, fosfato e silicato) foram analisados através do método descrito por Strickland e Parsons (1965) e Grasshoff et al. (1983).

Os dados fitoplanctônicos foram obtidos nas mesmas estações dos dados hidrológicos. Amostragens foram feitas a cada 3 horas, num ciclo de 12 horas, com o auxílio de rede de plâncton, com $1 \mathrm{~m}$ de comprimento, $30 \mathrm{~cm}$ de diâmetro de boca, e com $65 \mu \mathrm{m}$ de abertura de malha. Esta rede foi arrastada horizontalmente à superfície por 5 minutos, com o barco em velocidade lenta e constante. Após as coletas as amostras foram fixadas com formol neutro a $4 \%$

Em laboratório, foi feita a medição da biomassa através do peso úmido. A análise qualitativa do fitoplâncton foi realizada com base em subamostras de $0,5 \mathrm{ml}$, retiradas da amostra total, colocadas em lâminas e levadas ao microscópio composto. Na identificação das espécies foram utilizadas dentre outras as obras de: Cumming et al (1995), Mizuno (1968), Prescott (1975).

Dados climatológicos

\section{RESULTADOS}

O valor médio mínimo da temperatura do ar, para o período de 1963 a 1990, foi de $23,0^{\circ} \mathrm{C}$, nos meses de julho e agosto, e o máximo foi de $27,2^{0} \mathrm{C}$ para o mês de janeiro. Os dados médios da precipitação pluviométrica, para o período de 1963 a 1990 , variaram de um mínimo de 33,1 mm, em janeiro, a um máximo de 185,9 mm em maio. A média do total acumulado foi de $1.141,5 \mathrm{~mm}_{\text {ano }}{ }^{-1}$. A taxa média mínima de evaporação, para o período de 1963 a 1990, foi de 71,1 mm em junho, e o máximo foi de $216 \mathrm{~mm}$ em dezembro . O valor médio mínimo, para o período de 1963 a 1990, foi de 162,8 h.dec ${ }^{-1}$, em junho; o máximo foi 237,1 h.dec ${ }^{-1}$ em janeiro. O valor médio 
mínimo da umidade relativa do ar foi de $70 \%$ em dezembro e o máximo foi de $86 \%$, em junho (Tabela 1).

Tabela 1 - Normal climatológica da Estação de Propriá, Estado de Sergipe, referente ao período de 1963 a 1990.

\begin{tabular}{l|c|c|c|c|c}
\hline Meses & $\begin{array}{c}\text { Temperatura } \\
\text { Média } \\
\left({ }^{\circ} \mathrm{C}\right)\end{array}$ & $\begin{array}{c}\text { Precipitação } \\
(\mathrm{mm})\end{array}$ & $\begin{array}{c}\text { Evaporação } \\
(\mathrm{mm})\end{array}$ & $\begin{array}{c}\text { Insolação } \\
(\mathrm{h} / \mathrm{dec})\end{array}$ & $\begin{array}{c}\text { Umidade } \\
\text { Relativa } \\
(\%)\end{array}$ \\
\hline Janeiro & 27,2 & 33,1 & 214,4 & 237,1 & 73 \\
Fevereiro & 27,0 & 57,5 & 175,5 & 202,9 & 74 \\
Março & 27,1 & 87,7 & 161,1 & 209,4 & 77 \\
Abril & 26,3 & 166,8 & 121,5 & 175,8 & 81 \\
Maio & 25,0 & 185,9 & 83,7 & 181,3 & 85 \\
Junho & 23,9 & 166,8 & 71,1 & 162,8 & 86 \\
Julho & 23,0 & 158,0 & 78,4 & 168,5 & 85 \\
Agosto & 23,0 & 84,9 & 93,1 & 189,1 & 83 \\
Setembro & 23,9 & 73,3 & 127,3 & 188,4 & 78 \\
Outubro & 25,1 & 42,2 & 180,1 & 223,4 & 76 \\
Novembro & 26,5 & 36,7 & 215,4 & 230,9 & 73 \\
Dezembro & 26,7 & 48,6 & 216,0 & 232,9 & 70 \\
\hline
\end{tabular}

Fonte: IV Distrito de Meteorologia Salvador, Bahia, do Instituto Nacional de Meteorologia - INMET

Dados hidrológicos

A altura da maré no período chuvoso apresentou um mínimo de $0,3 \mathrm{~m}$ às $10: 34 \mathrm{~h}(04 / 08 / 97)$ e às 11:02 h (05/08/97) e um máximo de 2,2 màs 04:09 h (04/08/97) e às $04: 43 \mathrm{~h}(05 / 08 / 97)$. No período seco, o mínimo foi de $0,0 \mathrm{~m}$ às 23:09 $\mathrm{h}(13 / 01 / 98)$ e o máximo 1,9 m às 16:02 h (12/01/98) e às 16:43 h (13/01/98) (Tab. 2).

No período chuvoso, o mínimo de profundidade na estação 1 foi de $3,7 \mathrm{~m}$ às 10:00 h (baixa-mar) do período seco, e o máximo foi de 6,2 $\mathrm{m}$ às 17:00 h (preamar) do período chuvoso, apresentando uma profundidade média total de 4,9 m. Na estação 2, o mínimo foi de 4,5 m às 10:30 h (baixa-mar) do período seco e o máximo foi de $6,5 \mathrm{~m}$ às 16:30 h (preamar) deste mesmo período, sendo a profundidade média 5,6 m (Tab. 2).

O mínimo de transparência da água na estação 1 foi de $0,5 \mathrm{~m}$ às 11:00 h (baixa mar) no período chuvoso e o máximo foi de 2,5 $\mathrm{m}$ às 13:00 h (maré enchente) no período seco. Na estação 2, o mínimo foi de 0,7 $\mathrm{m}$ às 16:00 h (preamar) do período chuvoso e o máximo foi de 2,5 $\mathrm{m}$ às $16: 30 \mathrm{~h}$ (preamar) do período seco (Tab. 2).

$\mathrm{Na}$ estação 1 o mínimo de temperatura da água foi de $25,0^{\circ} \mathrm{C}$ às $8: 00 \mathrm{~h}$ (maré secante) e às 14:00 h (maré enchente), na camada superficial do período chuvoso e o máximo foi de $30,0^{\circ} \mathrm{C}$ às $16: 00 \mathrm{~h}$ (preamar), na camada superficial do período seco. Na estação 2, a temperatura da água variou de $24,9^{0} \mathrm{C}$ às 10:00 h (baixa-mar), camada do fundo do período chuvoso a $29,8^{0} \mathrm{C}$ às $7: 30 \mathrm{~h}$ (maré secante), camada do fundo do 
período seco. De uma forma geral, a temperatura foi mais elevada no período seco (Tab. 2). 
Tabela 2 - Dados hidrológicos do sistema estuarino do rio São Francisco, em Brejo Grande, Sergipe, em 04 e 05/08/97 (período chuvoso) e 12 e 13/01/98 (período seco). MS=maré secante, $\mathrm{BM}=$ baixa-mar, $\mathrm{ME}=$ maré enchente, $\mathrm{PM}=$ preamar. $\mathrm{S}=$ superfície, $\mathrm{F}=$ fundo.

\begin{tabular}{|c|c|c|c|c|c|c|c|c|c|c|c|c|c|}
\hline $\begin{array}{l}\text { PERI- } \\
\text { ODO }\end{array}$ & $\begin{array}{l}\text { ESTA- } \\
\text { ÇÃOO }\end{array}$ & $\begin{array}{l}\text { HORA } \\
\text { (MARÉ) }\end{array}$ & $\begin{array}{l}\text { CAMA } \\
\text { DA }^{-1}\end{array}$ & $\begin{array}{l}\text { PROFUN- } \\
\text { DIDADE } \\
(\mathrm{m})\end{array}$ & $\begin{array}{l}\text { TRANSPA- } \\
\text { RÊNCIA } \\
(\mathrm{m})\end{array}$ & $\begin{array}{l}\text { TEMPERA- } \\
\text { TURA }\left({ }^{\circ} \mathrm{C}\right)\end{array}$ & $\begin{array}{l}\text { SALINIDA- } \\
\text { DE }(\% 0)\end{array}$ & $\begin{array}{c}\mathrm{O}_{2} \\
\left(\mathrm{ml} . \mathrm{I}^{-1}\right)\end{array}$ & $\mathrm{Ph}$ & $\begin{array}{c}\mathrm{NO}_{3} \\
\text { (ug.at. } .^{-1} \text { ) }\end{array}$ & $\begin{array}{c}\mathrm{NO}_{4} \\
\text { (ug.at. }\left.\right|^{-1} \text { ) }\end{array}$ & $\begin{array}{c}\mathrm{PO}_{4} \\
\text { (ug.at. }\left.\right|^{-1} \text { ) }\end{array}$ & $\begin{array}{c}\mathrm{SiO}_{2} \\
\text { (ug.at. } .^{-1} \text { ) }\end{array}$ \\
\hline & \multirow{8}{*}{1} & 08:00 & $\bar{S}$ & & & 25,00 & 0,04 & 5,89 & 7,40 & 0,112 & 11,640 & 0,269 & 76,421 \\
\hline & & (MS) & $F$ & 5,80 & 1,00 & 25,30 & 0,53 & 6,63 & 7,30 & 0,112 & 11,606 & 0,299 & 23,440 \\
\hline & & $11: 00$ & $S$ & & & 25,20 & 0,05 & 6,08 & 7,31 & 0,122 & 11,508 & 0,269 & 86,421 \\
\hline & & (BM) & $\mathrm{F}$ & 4,30 & 0,50 & 25,70 & 0,05 & 6,15 & 7,60 & 0,132 & 11,597 & 0,269 & 72,797 \\
\hline & & $14: 00$ & $S$ & & & 25,00 & 0,04 & 6,33 & 7,01 & 0,092 & 11,845 & 0,279 & 65,229 \\
\hline C & & (ME) & $F$ & 4,50 & 0,75 & 25,50 & 0,04 & 6,22 & 7,07 & 0,132 & 12,961 & 0,308 & 70,412 \\
\hline $\mathrm{H}$ & & $17: 00$ & $S$ & & & 25,70 & 0,13 & 6,34 & 7,23 & 0,122 & 11,702 & 0,299 & 63,898 \\
\hline U & & (PM) & $F$ & 6,20 & 0,75 & 25,10 & 0,27 & 6,06 & 7,50 & 0,092 & 11,269 & 0,229 & 25,596 \\
\hline V & \multirow{8}{*}{2} & 07:00 & $S$ & \multirow{3}{*}{6,02} & \multirow{3}{*}{0,75} & 25,40 & 0,04 & 6,52 & 7,20 & 0,071 & 13,413 & 0,328 & 76,972 \\
\hline 0 & & (MS) & $\mathrm{F}$ & & & 25,10 & 0,04 & 6,32 & 7,15 & 0,082 & 12,912 & 0,279 & 47,843 \\
\hline $\mathrm{S}$ & & $10: 00$ & S & & & 25,10 & 0,04 & 6,11 & 7,10 & 0,112 & 12,355 & 0,468 & 65,917 \\
\hline \multirow[t]{5}{*}{0} & & (BM) & $F$ & \multirow[t]{2}{*}{5,20} & \multirow[t]{2}{*}{0,75} & 24,90 & 0,04 & 5,99 & 7,10 & 0,082 & 13,367 & 0,279 & 58,531 \\
\hline & & $13: 00$ & $S$ & & & 25,40 & 0,04 & 6,19 & 7,42 & 0,041 & 12,740 & 0,119 & 146,237 \\
\hline & & (ME) & $F$ & \multirow[t]{2}{*}{6,00} & \multirow[t]{2}{*}{0,75} & 25,70 & 0,04 & 6,17 & 7,59 & 0,061 & 12,067 & 0,129 & 149,035 \\
\hline & & $16: 00$ & $S$ & & & 25,50 & 0,04 & 6,28 & 7,28 & 0,061 & 12,541 & 0,139 & 95,045 \\
\hline & & (PM) & $F$ & 6,00 & 0,70 & 25,60 & 0,04 & 6,01 & 7,26 & 0,071 & 12,490 & 0,090 & 85,733 \\
\hline \multirow{8}{*}{ S } & \multirow{8}{*}{1} & 07:00 & $S$ & \multirow{3}{*}{4,00} & \multirow{3}{*}{1,25} & 29,40 & 15,93 & 5,00 & 7,12 & 0,001 & 0,501 & 0,199 & 102,292 \\
\hline & & (MS) & $F$ & & & 29,20 & 27,35 & 4,90 & 7,74 & 0,001 & 0,718 & 0,129 & 163,943 \\
\hline & & $10: 00$ & $S$ & & & 29,50 & 0,80 & 5,10 & 7,25 & 0,001 & 0,573 & 0,129 & 122,521 \\
\hline & & (BM) & $F$ & \multirow[t]{2}{*}{3,70} & \multirow[t]{2}{*}{1,50} & 29,40 & 2,39 & 4,70 & 7,13 & 0,001 & 0,649 & 0,149 & 90,870 \\
\hline & & $13: 00$ & $S$ & & & 29,70 & 0,80 & 5,30 & 7,43 & 0,001 & 0,693 & 0,159 & 116,375 \\
\hline & & (ME) & $\mathrm{F}$ & \multirow[t]{2}{*}{5,00} & \multirow[t]{2}{*}{2,50} & 29,50 & 2,39 & 4,80 & 7,41 & 0,001 & 0,788 & 0,139 & 126,879 \\
\hline & & $16: 00$ & $S$ & & & 30,00 & 3,72 & 4,80 & 7,61 & 0,001 & 0,623 & 0,378 & 223,438 \\
\hline & & (PM) & $F$ & 6,00 & 1,75 & 29,70 & 17,00 & 4,60 & 7,59 & 0,020 & 0,675 & 0,100 & 177,979 \\
\hline C & \multirow{8}{*}{2} & $07: 30$ & $S$ & \multirow{3}{*}{5,00} & \multirow{3}{*}{1,00} & 29,20 & 0,66 & 4,90 & 7,59 & 0,041 & 0,513 & 0,400 & 226,328 \\
\hline \multirow[t]{7}{*}{0} & & (MS) & $\mathrm{F}$ & & & 29,80 & 0,80 & 4,80 & 7,40 & 0,031 & 0,595 & 0,328 & 138,714 \\
\hline & & $10: 30$ & $S$ & & & 29,00 & 0,80 & 5,30 & 7,40 & 0,031 & 0,545 & 0,050 & 187,383 \\
\hline & & (BM) & $F$ & \multirow[t]{2}{*}{4,50} & \multirow[t]{2}{*}{1,50} & 29,10 & 0,80 & 4,70 & 7,35 & 0,041 & 0,703 & 0,030 & 196,007 \\
\hline & & $13: 30$ & $S$ & & & 29,30 & 0,80 & 5,20 & 7,30 & 0,041 & 0,583 & 0,050 & 175,687 \\
\hline & & (ME) & $\mathrm{F}$ & \multirow[t]{2}{*}{5,50} & \multirow[t]{2}{*}{2,25} & 29,50 & 0,80 & 4,80 & 7,60 & 0,001 & 0,602 & 0,090 & 187,245 \\
\hline & & $16: 30$ & $S$ & & & 29,20 & 0,80 & 5,50 & 7,50 & 0,001 & 0,573 & 0,050 & 166,512 \\
\hline & & (PM) & $\mathrm{F}$ & 6,50 & 2,50 & 29,40 & 0,80 & 5,00 & 7,68 & 0,001 & 0,547 & 0,179 & 239,034 \\
\hline
\end{tabular}


A salinidade apresentou durante o período chuvoso, um mínimo de $0,04 \%$ o em várias marés, e um máximo de 0,53\%o às 8:00 h (maré secante), amostra de fundo da estação 1. A amplitude foi muito baixa com $0,49 \%$ o. No período seco, o mínimo foi $0,80 \%$ o em quase todas as marés da estação 2 , tanto na superfície como no fundo, e o máximo foi $27,35 \%$ às 7:00 h (maré secante), camada de fundo da estação 1 (Tab. 2). A amplitude para este período foi de 26,55\%o.

Com relação ao $\mathrm{pH}$, este apresentou-se variando de neutro a alcalino, com valores levemente mais altos no período seco. O mínimo foi de 7,01 às 14:00 h (maré enchente) na camada superficial da estação 1, no período chuvoso; e o máximo foi de 7,74 às 7:00 h (maré secante) na camada do fundo da estação 1, no período seco (Tab. 2).

O oxigênio dissolvido variou de um mínimo de 4,7 ml. $\mathrm{l}^{-1}$ às 13:00 e 13:30 h (baixa-mares) das estações 1 e 2, camada do fundo do período seco a um máximo de $6,63 \mathrm{mll}^{-1}$ às $08: 00 \mathrm{~h}$ (maré secante), camada do fundo da estação 1 no período chuvoso. De uma forma geral, o oxigênio dissolvido manteve-se alto, com valores mais elevados no período chuvoso (Tab. 2).

$\mathrm{O}$ nitrito-N apresentou maior quantidade no período chuvoso, na estação $1 \mathrm{e}$ camada mais profunda, enquanto que no período seco a estação 2 apresentou maior quantidade de nitrito na camada superficial que a estação 1. É interessante observar um comportamento inverso entre as camadas de superfície e fundo. O mínimo geral foi de 0,01 $\mu$ gat. $1^{-1}$ em várias marés do ciclo diurno do período seco e o máximo geral foi de 0,132 $\mu$ gat..$^{-1}$ ÀS 17:00 h (maré enchente), na camada de fundo (Tab. 2).

$\mathrm{O}$ nitrato- $\mathrm{N}$ apresentou quantidades muito mais elevadas no período chuvoso, tendo as duas estações estudadas e diversas camadas concentrações equivalentes. $\mathrm{O}$ mínimo geral foi $0,501 \mu$ gat. $1^{-1}$, às 7:30 h (maré secante), camada superficial, na estação 2 do período seco. O máximo geral foi de $13,413 \mu$ gat. $^{-1}$ às 7:00 h (maré secante), camada superficial, na estação 2 do período chuvoso (Tab. 2).

$\mathrm{O}$ fosfato-P oscilou bastante com pouca diferença entre os períodos chuvoso e seco. As maiores variações ocorreram entre as marés diurnas. Valores mais elevados foram registrados na baixa-mar do período chuvoso e na preamar e maré secante do período seco. O mínimo geral foi $0,030 \mu$ gat. $^{-1}$ às 10:30 h (baixa-mar), na camada de fundo da estação 2 , no período seco. O máximo geral foi de $0,468 \mu$ gat. $1^{-1}$ na camada superficial da estação 2 , às $10 \mathrm{~h}$ (baixa-mar) do período chuvoso (Tab. 2).

$\mathrm{O}$ silicato-Si apresentou valores mais altos no período seco e na estação 2. Maiores diferenças de concentrações foram registradas entre as marés. O mínimo geral foi de 23,440 $\mu$ gat. $1^{-1}$ às $8: 00 \mathrm{~h}$ (maré secante) na camada de fundo da estação 1 , durante o período chuvoso. O máximo geral foi de 239,034 $\mu$ gat. ${ }^{-1}$ às $16: 30 \mathrm{~h}$ (preamar) na camada de fundo da estação 2, durante o período seco (Tab. 2).

Biomassa do plâncton

A biomassa planctônica obtida com a rede de $65 \mu \mathrm{m}$ foi maior no período seco, na estação 1 e durante as marés secantes e baixa-mares. O valor mínimo no período 22 
chuvoso foi de $32 \mathrm{mg} \cdot \mathrm{m}^{-3}$ na preamar da estação 2 e o máximo foi de $422 \mathrm{mg} \cdot \mathrm{m}^{-3}$ na baixa-mar da estação 1 . No período seco, o mínimo foi de $10 \mathrm{mg} \cdot \mathrm{m}^{-3}$ na preamar da estação 1 e o máximo foi de $1217 \mathrm{mg} . \mathrm{m}^{-3}$ na maré secante desta mesma estação. A média geral para a estação 1 no período chuvoso foi de $157 \mathrm{mg} \cdot \mathrm{m}^{-3}$ e para a estação 2 de $102 \mathrm{mg} \cdot \mathrm{m}^{-3}$; no período seco a média para a estação 1 foi de $521 \mathrm{mg} \cdot \mathrm{m}^{-3}$ quase o triplo do período chuvoso, e para a estação 2 foi de $241 \mathrm{mg} \cdot \mathrm{m}^{-3}$, um pouco mais do que o dobro do período chuvoso.

Fitoplâncton

Foram identificadas 59 espécies do fitoplâncton, pertencentes às Divisões Cyanophyta, Chrysophyta e Chlorophyta. Para o período chuvoso foram registradas 31 taxa (15 Chrysophyta, 13 Chlorophyta e 3 Cyanophyta) e para o período seco 38 taxa (20 Chlorophyta, 10 Chrysophyta e 8 Cyanophyta), destes apenas 15 são comuns aos dois períodos (Tabs. 3 e 4).

Quanto à abundância relativa foram significativas no período chuvoso as diatomáceas Aulacoseira granulata e Aulacoseira islandica f. curvata com percentuais totais variando de $60 \%$ na maré secante da estação 1 a $96 \%$ na preamar desta mesma estação (Tab. 3 e Fig. 2). No período seco predominou a clorofícea Dimorphococcus sp com mínimo de $8 \%$ na baixa-mar da estação 2 e máximo de $51 \%$ na maré enchente da estação 1. Foi ainda abundante na área Staurastrum leptocladum (Tab. 4 e Fig. 2).

Em termos de freqüência de ocorrência destacaram-se no período chuvoso com mais de $80 \%$ Aulacoseira granulata, Aulacoseira islandica f. curvata, Biddulphia laevis, Pediastrum biwae e Synedra ulna (Fig. 3). No período seco destacaram-se Dimorphococcus sp., Xanthidium sp, Aulacoseira granulata, Fragilaria capuccina, Spyrogira sp e Staurastrum leptocladum (Fig. 4). 
Tabela 3 - Abundância relativa do microfitoplâncton do rio São Francisco, em Brejo Grande, Sergipe, em 04 e 05/08/97 (período chuvoso). MS=maré secante, BM=baixa-mar, ME=maré enchente, $\mathrm{PM}=$ preamar.

\begin{tabular}{|c|c|c|c|c|c|c|c|c|}
\hline ESTAÇOEES & & & & & & & & \\
\hline MARES & MS & BM & ME & PM & MS & BM & ME & PM \\
\hline CYANOPHYTA & & & & & & & & \\
\hline Anabaena sp & 1 & 3 & & & & & 1 & \\
\hline Oscillatoria princeps Vaucher ex Gomont & & 2 & 1 & 1 & & & & \\
\hline Oscillatoria $\mathrm{sp}$ & & 2 & 1 & 1 & & 2 & & \\
\hline CHRYSOPHYTA & & & & & & & & \\
\hline Asterionella $\mathrm{sp}$ & 1 & & & & & & & \\
\hline Aulacoseira granulata G. H. K. Thwaites & 44 & 59 & 40 & 54 & 79 & 48 & 65 & 74 \\
\hline $\begin{array}{l}\text { Aulacoseira islandica f. curvata (Ehrenberg) } \\
\text { Otto Muller }\end{array}$ & 12 & 20 & 34 & 35 & 11 & 23 & 6 & 17 \\
\hline Bacillaria paxilifer (o.M.) Hendey & 2 & & 2 & & & & & \\
\hline Biddulphia laevis Ehrenberg & 7 & 6 & 1 & 1 & 1 & 7 & 1 & 1 \\
\hline Campylodiscus sp & & & & 1 & & & & \\
\hline Coscinodiscus sp & & & & & & & & 1 \\
\hline Diatomácea Centricae & 1 & & & & & & & \\
\hline Diatomácea Pennatae & 1 & & & & & & 1 & \\
\hline Fragilaria capuccina Desmazières \& Kützing & 1 & & 2 & & & & & \\
\hline Nitzschia $\mathrm{sp}$ & & & & 1 & & 1 & & \\
\hline Pleurosigma sp & & 1 & & & & & 1 & 1 \\
\hline Surirella $\mathrm{sp}$ & & & & & & 1 & 1 & 1 \\
\hline Synedra ulna (Nitzsch) Ehrenberg & 2 & 2 & 1 & 1 & 1 & 2 & 1 & \\
\hline Terpsinoe sp & 2 & & & & & & & \\
\hline CHLOROPHYTA & & & & & & & & \\
\hline Closterium setaceum Ehrenberg & 1 & & & 1 & 2 & & & \\
\hline Closterium sp & & & & & & & & 1 \\
\hline Eudorina elegans Ehrenberg & 4 & 3 & 5 & & 2 & 1 & 7 & \\
\hline Gloeocystis sp & & & & & & & & 1 \\
\hline Micrasterias laticeps Krieger & & & 2 & & & & & \\
\hline Micrasterias sp & & & & 1 & & & & \\
\hline Pediastrum biwae Negore & 5 & 2 & 3 & 1 & 1 & 3 & & 1 \\
\hline Pediastrum sp & & & & & 1 & & & \\
\hline Scenedesmus quadricauda (Turpin) Brébisson & & & 3 & & & & & \\
\hline Spyrogira sp & 9 & & 2 & & 2 & 11 & 14 & \\
\hline Staurastrum leptocladum Nordstedt & 5 & & 3 & 1 & & 1 & 2 & 2 \\
\hline Staurodesmum sp & & & & 1 & & & & \\
\hline Volvox aureus Ehrenberg & 2 & & & & & & & \\
\hline TOTAL & 100 & 100 & 100 & 100 & 100 & 100 & 100 & 100 \\
\hline
\end{tabular}


Tabela 4 - Abundância relativa do microfitoplâncton do rio São Francisco, em Brejo Grande, Sergipe, em 12 e 13/01/98 (período seco). $\mathrm{MS}=$ maré secante, $\mathrm{BM}=$ baixa-mar, $\mathrm{ME}=$ maré enchente, $\mathrm{PM}=$ preamar

\begin{tabular}{|c|c|c|c|c|c|c|c|c|}
\hline ESTAÇÖES & & & & & & & & \\
\hline MARES & MS & BM & ME & PM & MS & $\mathrm{BM}$ & ME & PM \\
\hline CYANOPHYTA & & & & & & & & \\
\hline Anabaena spiroides Klebahn & & & 2 & & & & & 5 \\
\hline Aphanocapsa sp & 1 & & 1 & & 2 & 5 & & \\
\hline Chroococcus sp & 5 & & & 6 & & 4 & & \\
\hline Lyngbya sp & & 1 & & & & 1 & 5 & \\
\hline Merismopedia convoluta Brébisson & & & 3 & & & & & \\
\hline Merismopedia punctata Meyen & 3 & 1 & & & & & & \\
\hline Microcystis sp & & & & 2 & & & & 2 \\
\hline Oscillatoria sp & & 1 & 1 & 1 & & & & \\
\hline CHRYSOPHYTA & & & & & & & & \\
\hline Aulacoseira granulata G. H. K. Thwaites & 7 & 6 & 2 & 14 & 23 & & 5 & 3 \\
\hline Biddulphia laevis Ehrenberg & & & & & & 4 & & \\
\hline Coscinodiscus sp & 1 & 1 & & & & & & \\
\hline Dinobryon sp & & 1 & & & & & & \\
\hline Ceratoneis arcus (Ehrenberg) Kutzing & 1 & & & 1 & & & & \\
\hline Fragilaria capuccina Desmazières \& Kützing & 3 & 5 & 3 & & 7 & 1 & 3 & 2 \\
\hline Lyrella lyra (Ehrenberg) Kanayeva & 1 & & & & & & & \\
\hline Nitzschia sp & & 2 & 1 & 4 & & & & 1 \\
\hline Surirella $\mathrm{sp}$ & & & & & 1 & & & \\
\hline Synedra ulna (Nitzsch) Ehrenberg & 3 & 5 & 3 & & & 1 & & \\
\hline CHLOROPHYTA & & & & & & & & \\
\hline Arthrodesmus sp & & & & 3 & & & & 15 \\
\hline Chaetophora sp & 4 & 1 & 11 & & & 3 & & \\
\hline Cosmarium sp & & 1 & & & 1 & 2 & 7 & \\
\hline Desmidium sp & 1 & & 1 & & 1 & & & \\
\hline Dimorphococcus sp & 35 & 39 & 51 & 37 & 15 & 8 & 46 & 45 \\
\hline Eudorina elegans Ehrenberg & 4 & 8 & & & & & 4 & \\
\hline Gloeocystis sp & & & & & & & & 5 \\
\hline Golenkinia sp & & & & & & 1 & & \\
\hline Gonatozygon sp & 4 & 12 & 4 & & 5 & 1 & 5 & \\
\hline Micrasterias radians Turner & & & & & & 3 & & \\
\hline Onychonema sp & & 1 & 1 & 1 & & & & \\
\hline Pandorina sp & & & & & 1 & 5 & 3 & \\
\hline Pediastrum biwae Negore & 1 & 1 & & & 1 & 2 & 1 & 9 \\
\hline Pediastrum simplex (Meyen) Lemmermann & 1 & & & & 1 & & 2 & \\
\hline Spyrogira sp & 2 & 7 & 4 & 2 & 7 & 10 & & 11 \\
\hline Staurastrum gracile Ralfs & 1 & & 2 & 1 & & 1 & & \\
\hline Staurastrum leptocladum Nordstedt & 15 & 1 & 10 & 18 & 21 & 29 & 13 & \\
\hline Staurastrum sp & 1 & & & 1 & 1 & 10 & & \\
\hline Staurodesmus sp & 3 & 4 & & 4 & & 8 & 3 & \\
\hline Xanthidium sp & 3 & 2 & 2 & 5 & 13 & 1 & 3 & 7 \\
\hline TOTAL & 100 & $\overline{100}$ & $\overline{100}$ & 100 & 100 & 100 & 100 & 100 \\
\hline
\end{tabular}




\section{PERÍODO CHUVOSO}

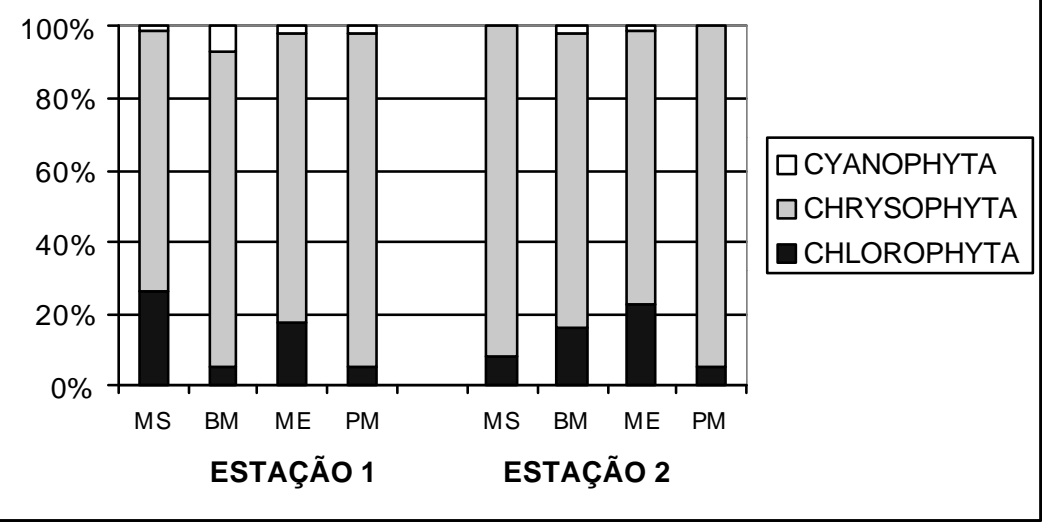

\section{PERÍODO SECO}

Figura 2 - Abundância relativa do microfitoplâncton do estuário do rio São Francisco, em Brejo Grande, Sergipe, em 04 e 05/08/97 (período chuvoso) e em 12 e 13/01/98 (período seco). 


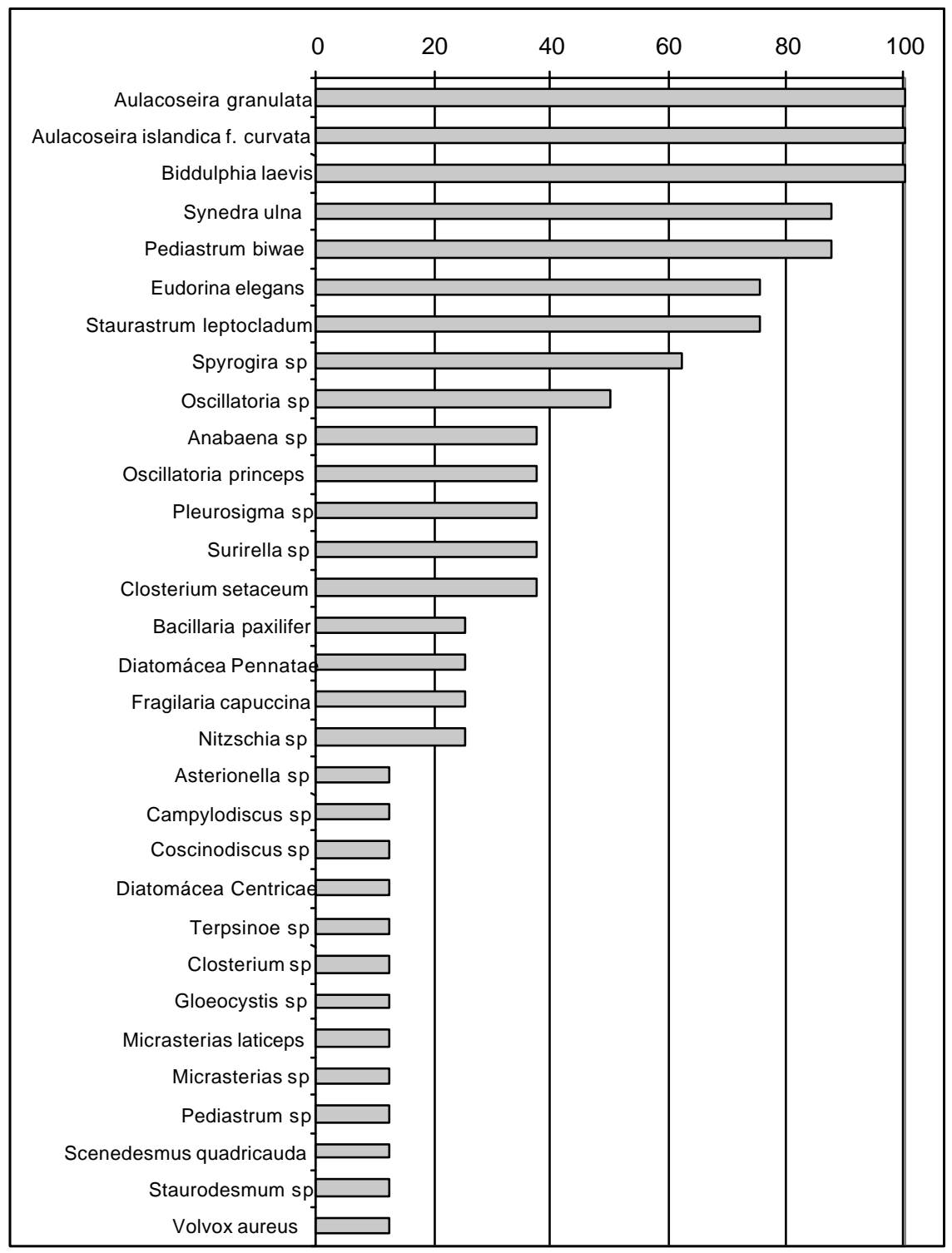

Figura 3 - Freqüência de ocorrência do microfitoplâncton no sistema estuarino do rio São Francisco, em Brejo Grande, Sergipe, em 04 e 05/08/97 (período chuvoso) . 


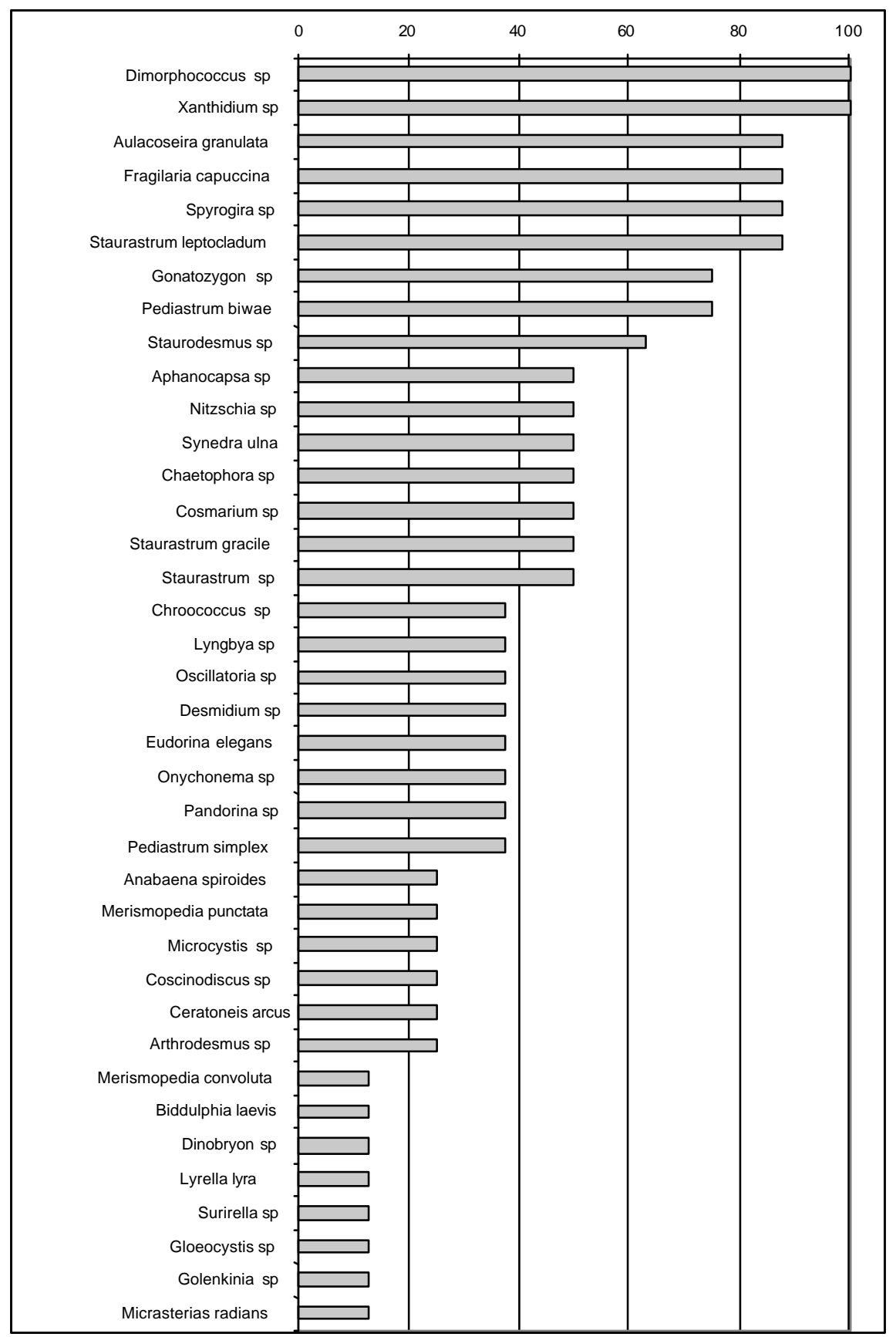

Figura 4 - Abundância relativa do microfitoplâncton no sistema estuarino do rio São Francisco, em Brejo Grande, Sergipe, em 12 e 13/01/98 (período seco). 


\section{DISCUSSÃO}

O rio São Francisco nasce na serra da Canastra, em Minas Gerais e percorre $3.100 \mathrm{~km}$, desde sua nascente até sua foz no oceano Atlântico, entre os municípios de Brejo Grande, em Sergipe, e Piaçabuçu, em Alagoas. Drena uma bacia hidrográfica de aproximadamente $640.000 \mathrm{~km}^{2}$ (CODEVASF, 1996). Por ser o principal rio do Nordeste brasileiro tem sido intensamente utilizado em toda sua extensão quer para a geração de energia elétrica, irrigação, abastecimento de cidades e receptor de resíduos orgânicos e inorgânicos das mais diversas fontes.

Sabe-se, que as regiões estuarinas e marinhas costeiras são responsáveis por aproximadamente $20 \%$ da produção primária global, mesmo representando apenas de 1 a 2\% da área otal dos oceanos (Duarte, 1995). No caso do rio São Francisco a contribuição à região costeira se destacava no cenário nacional, devido ao grande volume d'água envolvido, fertilizando vastas áreas e se constituindo num grande celeiro para a pesca. Segundo Uribe et al. (1988) a produção primária da várzea da Marituba, antes dos projetos da CODEVASF, contribuíam na riqueza do rio São Francisco e área costeira adjacente.

$\mathrm{Na}$ realidade, a área próxima à foz que antes era um estuário típico e altamente produtivo, passou a ser no decorrer dos anos, um sistema dominado fortemente pelo fluxo limnético com queda na produção pesqueira (Marques, 1992). Além disto, os manguezais que antes recobriam parte da desembocadura e contribuíam para a riqueza local ficou reduzido às áreas dos canais que meandram pelo continente.

Os estuários são caracterizados por um grande dinamismo, por estarem constantemente recebendo fluxos marinho e limnético que se misturam (Mclusky, 1989). A circulação dentro de um estuário é dirigida pelo movimento de marés, correntes, distribuição interna de densidades e forças sinópticas do vento, sendo a primeira a mais importante, uma vez que conduz o transporte e troca de materiais entre os ambientes fluviais, estuarinos e marinhos. $\mathrm{Na}$ foz de um estuário, os processos de mistura da água doce e salgada durante as marés, provocam uma variação nos parâmetros físicos, químicos e biológicos, num período semi-diurno (Fan e Jin, 1989). Dessa forma, os estudos realizados na foz do São Francisco foram feitos em um ciclo diurno das marés para se conhecer a hidrologia e o fitoplâncton em todas as suas variáveis.

Nas regiões estuarinas tropicais, o parâmetro hidrológico principal depois das marés é a salinidade que condiciona a distribuição das espécies, uma vez que a temperatura tem pequena amplitude de variação. Em estuários tropicais onde as variações de temperatura são mínimas a distribuição e abundância do fitoplâncton está intimamente associada a salinidade (Tundisi, 1970).

Desta forma, a salinidade no sis tema estuarino do rio São Francisco apresentou características de mistura intensa dos fluxos marinho e limnético, com predomínio do limnético, podendo ser classificado como homogêneo (tipo C) no período chuvoso e fortemente estratificado na sua foz no período seco (tipo A) de acordo com o sistema esquematizado por Tundisi (1970).

Trab. Oceanog. Univ. Fed. PE, Recife, 27(1):15-32, 1999. 
Segundo a classificação das águas, apresentada no Simpósio de Veneza, em 1959, o estuário teve um regime polialino a limnético, predominando este último. Esta maior influência limnética no sistema estuarino do rio São Francisco se faz sentir até as partes próximas à desembocadura, onde no período chuvoso chega a $0,04 \%$ o.

Apesar da grande carga de dejetos que recebe, o oxigênio dissolvido apresentou altos teores uma vez que o rio drena um volume de água muito grande e a correnteza permite uma circulação rápida, sendo as águas classificadas de acordo com Macêdo e Costa (1978) como zona sem poluíção.

A água estuarina não é simplesmente água do mar diluída. Existem concentrações de outros íons tais como fosfato, nitrato e silicato, que são mais abundantes na água do rio do que no mar, havendo tendência de diminuir suas concentrações no sentido montante-jusante (McLusky, 1989). Este fato foi comprovado para o estuário do rio São Francisco, quando os nutrientes apresentaram no período chuvoso altas concentrações, principalmente de nitrato. Embora o período chuvoso coincida com menor vazão do rio, muito dos nutrientes entram no estuário vindo da lixiviação de terras das várzeas pelas chuvas, cujos monocultivos requerem intensa fertilização à base de nitrogênio, fósforo e potássio. A própria água da chuva trás grandes concentrações de nitrogênio.

O nitrogênio é consumido, principalmente pelas cianofíceas, as quais predominam nas áreas marginais do rio São Francisco em determinadas épocas, causando uma coloração esverdeada intensa na água, fenômeno denominado por "verdeto". O grande desenvolvimento de cianofíceas, leva a um decréscimo do oxigênio dissolvido nas áreas próximas às margens, que as sociado à toxicidade destas microalgas causam mortalidade em alguns organismos (Souza, 1998).

Nas estações amostradas, o predomínio no fitoplâncton foi das diatomáceas no período chuvoso e das clorofíceas no período seco. A predominância das diatomáceas tem sido referido para a maioria dos estuários (Patrick, 1967) quando há maior influência do fluxo marinho. Quando em um estuário o predomínio é do fluxo limnético passam a dominar as clorofíceas (Smayda, 1983).

A biomassa planctônica foi bem maior no período seco próximo à desembocadura, sendo as clorofíceas Dimorphococcus sp e Staurastrum leptocladum as mais abundantes. Segundo Sommer (1989) as clorofíceas, entre elas Staurastrum cingulum, respondem rapidamente a pulsos de fósforo. Lackey (1967) menciona o conceito geral de o $\mathrm{PO}_{4}$ e o $\mathrm{NO}_{3}$ governam a abundância das clorofíceas. Segundo Lemos (comunicação verbal) o baixo São Francisco recebe no período seco uma carga de nutrientes à base de fósforo proveniente da agroindústria da cana-de-açúcar, uma das principais atividades desta área.

A maior biomassa fitoplanctônica no período chuvoso deveu-se a ressuspensão das diatomáceas Aulacoseira granulata e Aulacoseira islandica f. curvata, que se desenvolvem rapidamente em áreas próximas ao substrato durante períodos calmos. Como a transparência no estuário do rio São Francisco, no período seco foi alta, e a coluna da água apresentou períodos de estabilidade, o desenvolvimento dessa diatomácea foi otimizado, formando densas manchas. Quando os ventos aumentaram no período chuvoso, houve a ressuspensão destas espécies. Ressuspensão por vento foi 
registrado por Carick et al. (1993) para o lago Apopka, na Florida para a espécie Aulacoseira italica. Koening (1997) estudando o fitoplãncton do estuário do rio Ipojuca (PE), registrou um grande percentual de microalgas bentônicas as quais foram trazidas à lâmina d’água por processos de ressuspensão devido a pouca profundidade deste estuário.

\section{REFERÊNCIAS BIBLIOGRÁFICAS}

CARRICK, H. L.; ALDRIDGE, F. J.; SCHELSKE, C. L. Wind influences phytoplankton biomass and composition in a slallow, productive lake. Limnol. Oceanogr., 38:1179-1192, 1993.

CODEVASF. Projeto semi-árido: proposta de desenvolvimento sustentável da bacia do rio São Francisco e do semi-árido nordestino. Brasília, 1996. 60 p.

CUMMING, B. F., WILSON, S. E., HALL, R. I et al. Diatoms from Bristish Columbia (Canada) Lakes and their relationship to salinity, nutrients and other limnological variables. Bibliotheca Diatomologica, Band, 31, J. Cramer, Berlin, Stuttgart, 1-207, 1995.

DAY JR, J. W. e YÁÑEZ ARANCIBIA, A. 1982. Costal lagoons and estuaries: Ecosystems approach. Cienc. Interam., 22:11-26.

DUARTE, C. M. Submerged aquatic vegetation in relation to different nutrient regimes. Ophelia. Heldingor, v. 41, p. 87-112, feb. 1995.

FAN, A., JIN, X. Tidal effect on nutrient exchange in Xiangshan Bay, China. Marine Chemistry, Amsterdam, v. 27, n.3-4, p. 259-281, oct. 1989.

GRASSHOF, K.; EHRHARDT, M.; KREMLING, K. Methods of seawater analysis. 2ed. New York: Verlag Chemie, 1983. 419 p.

KETCHUM, B. H. 1983. Estuarine characteristics. In: B. H. Ketchum (ed). Estuaries and enclosed seas. New York, Elsevier Sci. Publ. Comp., p. 1-14.

KOENING, M. L. Ecologia e dinâmica do fitoplâncton no estuário do rio Ipojuca, após a implantação do porto de Suape (PE Brasil). Tese Doutorado, Universidade Federal Rural de Pernambuco, 1997. 263p+anexos.

LACKEY, J. B. The microbiota of Estuaries and their roles. In: Estuaries. Lauff, G. H., American Association for the Advancement of Science. 1967. p. 291-305.

MACÊDO, S. J., COSTA, K. M. P. Estudo ecológico da região de Itamaracá Pernambuco - Brasil. Condições hidrológicas do estuário do Rio Botafogo. Ciên. Cult., 30,.(7), p.346-368, 1978.

MARQUES, José Geraldo W. (Org.) O RIMA (Relatório de mpacto Ambiental) do poder e o Contra-RIMA dos deserdados: destruição e sobrevivência da Várzea da Marituba. São Paulo: Programa de Pesquisa e Conservação de Áreas Úmidas no Brasil da Universidade de São Paulo/ IDRC/ Fundação Ford, 1992. 127 p. (Relatório preliminar)

MCLUSKY, D. S. The estuarine ecosystem. 2. ed. New York: Chapman \& Hall, 1989. $215 \mathrm{p}$. 
MIZUNO, T. Illustrations of the freshwater plankton of Japan. Osaka: Hoikusha, 1968. $351 \mathrm{p}$.

ODUM, E. P. Ecologia. Rio de Janeiro, Interamericana, 1985. 434p.

PATRICK, R. Diatoms communities in estuaries. In: LAUFF, G. H. (Ed). Estuaries. Washington: AAAS, p.311-315, 1967.

PRESCOTT, G. W. How to know the freshwater algae. Pictured Key Nature Series. C. Brown Company Publishers, Dubuque, Lowa, 1975. 334 p.

SMAYDA, T. J. The plankton of estuaries. In: KETCHUM, B. H. (ed.) Estuaries and enclosed seas. Amsterdan: Elsevier, p. 65-112. 1983.

SOMMER, U. Plankton Ecology, succession in plankton communities. SpringerVerlag, Berlin, 1989.369p.

SOUZA, M. R. M. Impacto no estuário do rio São Francisco e conseqüências sócioeconômicas no município de Brejo Grande. Dissertação de Mestrado. Universidade Federal de Sergipe, 1998.

STRICKLAND, J. D. H, PARSONS, T.R. A manual of seawater analusis. Buletim of Fisheries Research Boor da of Canada, Ottawa, v. 125, p. 1-205, 1965.

TUNDISI, J. G. O plâncton estuarino. Contr. avulsas Inst. Oceanogr. São Paulo, sér. Ocean. Biol., 19: p.1-22, 1970.

URIBE, A. et al. Relatório preliminar sobre a viabilidade ambiental do anteprojeto CODEVASF/ECOPLAN de irrigação e drenagem da área da Marituba. Salvador: Hydros, 1988. 